\title{
Young and motivated for self-care? An interview study with young adults suffering from type 1 diabetes
}

\author{
Yvonne Hilli*1,2, Helena Lööf ${ }^{1}$, Josefina Malmberg ${ }^{1}$, Detlef Hess ${ }^{3}$ \\ ${ }^{1}$ University of Borås, Sweden \\ ${ }^{2}$ Nord University, Norway \\ ${ }^{3}$ Södra Älvsborg Hospital, Department of Diabetes and Endocrinology, Sweden
}

Received: February 20, 2018

DOI: $10.5430 /$ cns.v6n4p36
Accepted: May 1, $2018 \quad$ Online Published: May 4, 2018

URL: https://doi.org/10.5430/cns.v6n4p36

\begin{abstract}
Background: Europe has the largest number of children and adolescents with type 1 diabetes mellitus, 286,000 in total. One major goal in diabetes care is to minimise the risk of complications among patients by glycaemic control, medical check-ups and education to support patients' self-management and quality of life. The aim of the current study was designed to explore young adults' with type 1 diabetes and their motivation for self-care.

Methods: The present study had a qualitative design with a descriptive approach. A purposeful sample of eight $(n=8)$ young adults with type 1 diabetes and $\mathrm{HbA} 1 \mathrm{c}>70 \mathrm{mmol} / \mathrm{mol}$ were interviewed. A semi-structured interview with four open-ended questions was chosen as the method. The interviews were analysed using qualitative content analysis.

Results: The results revealed factors both promoting and hindering self-care. The first main category was "Factors promoting motivation for self-care" with three sub-categories: (1) feeling safe and getting support, (2) experiencing control over own life, and (3) striving for wellbeing and meaning in life. The second main category was "Factors that hindered motivation for self-care" with two sub-categories: (1) feelings of vulnerability, and (2) feeling excluded.

Conclusions: According to the results, motivation increases with positive response. Therefore a positive approach is of utmost importance when young adults come to the clinic for check-ups. Trying to always find something positive is of great significance for motivation and self-care. The focus should be on health and good experiences in life.
\end{abstract}

Key Words: Diabetes mellitus, Type 1, Interview, Motivation, Self-care, Young adults, Qualitative research

\section{INTRODUCTION}

Diabetes is one of the biggest health emergencies of the 21 st century, and its incidence has been on the increase. The estimated number of individuals with diabetes worldwide is around 415 million in the age group of 20-79 years, and of these, 58 million are in the Europe region alone. Europe has the highest incidence rate of children and adolescents with type 1 diabetes mellitus. ${ }^{[1]}$ In Sweden, 410,528 persons were registered with diabetes in 2016, and $90 \%$ of them had type 2 diabetes mellitus. ${ }^{[2]}$ Europe has the largest number of children and adolescents with type 1 diabetes mellitus, with the number of affected individuals amounting to 286,000 in total. $^{[1]}$

A major goal in diabetes care is to minimize the risk of complications in patients through glycaemic control, regular medical check-ups and education to support patients' selfmanagement and quality of life. ${ }^{[3-6]}$ The optimal HbA1c level for patients with type 1 diabetes mellitus is considered

*Correspondence: Yvonne Hilli; Email: yvonne.hilli@nord.no; Address: Nord University, Universitetsallén 11, 8026 Bodö, Norway. 
to be $<52 \mathrm{mmol} / \mathrm{mol}^{\left[{ }^{[1-3]}\right.}$ According to earlier studies and reports, among diabetes patients, young adults have higher than average HbA1c levels. ${ }^{[1,4,6]}$ The common complications are nerve damage, kidney damage and changes in the fundus oculi. Patients with type 1 diabetes, despite relatively good glycaemic control, could be at increased risk of premature death compared with people who do not have diabetes, but the risk is greater if glycaemic control is poor. ${ }^{[3,5,7,8]} \mathrm{A}$ high proportion of young adult patients with type 1 diabetes mellitus have $\mathrm{HbA} 1 \mathrm{c}$ levels over $70 \mathrm{mmol} / \mathrm{mol}$. These patients may have specific needs and require more frequent visits with nurses, doctors and other professionals on the diabetes team. One of the goals in the management of these patients is to achieve improved glycaemic control, but long periods between health check-ups can have a devastating impact on the outcome. In addition, reducing the HbAlc level might be very demanding for the patients in terms of lifestyle changes and monitoring of their blood glucose levels several times a day. This is also demanding for health personnel as it requires additional visits and more education and support for the patient. ${ }^{[3]}$

Being a young adult who is transitioning from childhood to adulthood is challenging. This transition involves physical, psychological and social changes, ${ }^{[8]}$ and this process typically occurs between the ages of 18 and 25 years. Young adults have unique needs in comparison with other age groups in terms of facing challenges. ${ }^{[4]}$ This transitional phase in life, which is defined as "emerging adulthood", is characterized by anxiety, selfishness, conflicts, disappointments and emotional crises. ${ }^{[9,10]}$ Being a young adult with diabetes mellitus, type 1 is even more challenging. Besides mastering all the challenges of normal development, there is also an expected and increased responsibility for self-care and their own health. ${ }^{[8]}$ Inconsistent behavioural patterns may make it difficult for young adults to follow treatment regimens and manage their glucose levels. ${ }^{[10]}$ Earlier studies on young adults living with type 1 diabetes mellitus and the additional care offered have demonstrated poor psychological and behavioural outcomes. ${ }^{[1-13]}$ In fact, many studies have shown deficiencies in the transition from child to adult care in patients with type 1 diabetes mellitus: It has been shown that young adults have difficulties complying with the requirements of traditional diabetes care for adults. ${ }^{[11,14-16]}$

Emerging adults might not fit well into the adult or paediatric diabetes care settings. Therefore, researchers and care providers have called for a new paradigm for the management of this age group and indicated the need for specific transitional clinics to be developed for the emerging adult population with type 1 diabetes mellitus. ${ }^{[5,14,17,18]}$ However, there is scarce empirical evidence on the obstacles faced by

Published by Sciedu Press this emerging adult population in diabetes care. ${ }^{[5]}$ Earlier studies have indicated that young adults value social support through group sessions, collaborative relationships and joint decision making with care providers. In addition, meeting the needs of the young adult population calls for more innovative methods and patient engagement. This might include joint consultation with a multi-disciplinary team, flexible access to advice and contact by e-mail or telephone. ${ }^{[4,12,18-20]}$ Maintaining self-care activities goes beyond knowing the recommendations. A trustful and supportive relationship with care providers has been shown to be very important for the translation of diabetes-related knowledge and skills into behaviour and for maintaining regular clinical attendance. ${ }^{[4,21]}$ Several studies have found that a successful transition is strongly associated with the quality of the care relationship. A humanistic and individualized care relationship is one where the nurse has a holistic approach, recognizing the young adult as a whole person and not only as a patient with type 1 diabetes. ${ }^{[22-29]}$ A person-centred care seems to be an important aspect for empowering and activating patients for self-management. Difficulties in establishing a trustful relationship is one of the factors underlying young adults discontinuing care and being lost to follow up. ${ }^{[25,27]}$ A recent study found that youth-specific diabetes service reduced the length of hospital stays caused by diabetic ketoacidosis. The costs associated with hospital admission were significantly reduced. ${ }^{[30]}$

Children with type 1 diabetes mellitus have regular checkups with doctors and nurses at child clinics. The care is family centred and the health care team is interprofessional; i.e. it includes counsellors, psychologists and dieticians. During childhood, parents are responsible for the diabetes care of the child. ${ }^{[21,31]}$ When a patient turns 18 years, he/she is automatically moved from child to adult care irrespective of their individual needs in terms of care. This transition means more responsibility for self-care as a result of increased independence and less contact with care givers. ${ }^{[21]}$ In Sweden, the recommendations for young adult outpatients with diabetes type 1 are counselling from the doctor once a year and counselling from the nurse at the clinic at least once a year. During the visits, the focus is on diet, physical activity, smoking and overall lifestyle. In addition, it is important that the patient set their own goals and that the goals be evaluated. ${ }^{[32]}$

At a hospital clinic in western Sweden, a major concern was that $36 \%$ of the young adult patients (age, 18-25 years) with diabetes mellitus type 1 had an HbA1c level $>70 \mathrm{mmol} / \mathrm{mol}$ compared to patients over 25 years, of whom only $21 \%$ had HbA1c levels $>70 \mathrm{mmol} / \mathrm{mol}$. There is strong evidence to show that HbA1c levels $>70 \mathrm{mmol} / \mathrm{mol}$ increase the risk of many severe complications and even early death. ${ }^{[1-3,5,8]}$ In 
an attempt to eliminate or reduce the number of young adult patients with $\mathrm{HbA} 1 \mathrm{c}$ levels $>70 \mathrm{mmol} / \mathrm{mol}$, a project was launched in 2016. ${ }^{[33]}$ The medical clinic for patient-centred care in this project is well developed. The young adult outpatients enrolled in this project have a yearly medical check-up with the doctor and two visits to the nurse until 25 year of age. Apart from following the national recommendations for diabetes, the focus is on the atmosphere and patient involvement and collaboration. The patient's journal is displayed on a TV screen and made visible to the patient. The patient's narrative is at the centre, and the patient's story is jointly documented in the patient's journal based on the patient's narrative. The patient's lifestyle and work and family situation are discussed as adjustment to everyday life. An assessment of the care based on glycaemic control is followed by an evaluation. Based on the evaluation, future care plans are discussed and the next visit is scheduled.

The current investigation was a sub-study that was conducted as part of this project with the aim of capturing the voice of young adult outpatients with HbA1c levels $>70 \mathrm{mmol} / \mathrm{mol}$. The purpose was to explore the patients' thoughts about their daily life and their motivation in terms of self-care and selfmanagement. The WHO (1986) defines health promotion as a process that enables people to increase their control over and improve their health; according to this definition, health is seen as a resource for everyday life and not the objective of living. ${ }^{[34]}$ The faculty at a university in western Sweden was contacted with a request to undertake this investigation. The clinic wanted the interviews to be conducted by nurse students studying for a master's degree, who had no prior connection to the clinic, so that the narratives would be as truthful as possible. The aim of the study was to understand the motivation for self-care among young adults with type 1 diabetes mellitus.

\section{RESEARCH DESIGN AND METHODS}

\subsection{Design, sampling and participants}

The present study had a qualitative design with a descriptive approach based on the general premises of a naturalistic inquiry. A qualitative design is appropriate when the aim is to explore the experience of the participants. In this study, a semi-structured interview with four-open ended questions was chosen. ${ }^{[35]}$ The interviews were analysed by qualitative content analysis. ${ }^{[36]}$ Twelve outpatients (age, 18-25 years) with diabetes mellitus type 1 who had HcA1c levels $>70 \mathrm{mmol} / \mathrm{mol}$ were recruited by nurses at the diabetes clinic from among registered patients at a hospital in western Sweden. The patients gave their consent to participate and were informed by the nurses about the study. To ensure the anonymity of the patients, a sample of eight participants were invited to be interviewed. The staff at the clinic were not informed about which patients participated. The participants who were selected were between 20 and 25 years of age and included four males and four females. Their age at the time of diagnosis varied between 1 and 16 years. All participants were Swedish natives. Six of the participants were living together with their boy- or girl-friend and two were living alone. A semi-structured interview guide was constructed in close cooperation with the staff at the medical clinic. The guide consisted of four main questions. The first open-ended question was: "Can you please tell me what motivates your self-care?" The following open-ended questions were about factors hindering motivation for self-care, experiences of support from professional care providers and how the participants perceived the connection between the HbA1c value and their health. Based on the participant's narrative, new questions were posed to get a deeper understanding of their self-care.

\subsection{Narrative interviews}

The participants were sent a letter with information about the study. The master students contacted the eight chosen participants and made an appointment for the interview. A pilot interview showed that the questions were relevant in relation to the aim of the study and did not need to be changed. The interview was therefore included in the study. The semistructured interviews were conducted by using the interview guide during week 41 and 42, 2016 in a quiet location at the hospital that was not connected with the medical clinic. The participants were encouraged to narrate their experiences in self-care. The emphasis was on creating a relaxed atmosphere where a conversation could take place. All interviews were audio taped and lasted for 20 to 40 minutes. The interviews were transcribed verbatim within one week after the interviews by the student who conducted the interview. The participants narrated willingly and provided rich material as is shown in the quotes. Each quote has an identification number, I1-I8.

\subsection{Ethical considerations}

According to Swedish law, ${ }^{[37]}$ ethical approval from an ethical committee was not required for this study. The study was approved by the head of the medical clinic at the hospital and conducted in every aspect in accordance with the guidelines of the Swedish Research Council. ${ }^{[38]}$ The participants were informed both orally and in writing about the aim of the study. Furthermore, the participants were informed that they could end the interview and withdraw without any explanation. They were also assured that the information they provided would be kept anonymous and confidential. 


\section{RESULTS AND DISCUSSION}

The aim of this study was to understand the motivation for self-care among young adults with type 1 diabetes mellitus. Based on the findings, factors that promote and hinder selfcare were identified. Two main themes emerged from the findings. Under the first one, "Factors promoting motivation for self-care", three sub-themes were identified: (1) feeling safe and getting support, (2) experiencing control over your own life, and (3) striving for wellbeing and meaning in life. Under the second theme, "Factors that hindered motivation for self-care", two sub-themes were identified: (1) feeling vulnerable, and (2) feeling excluded.

\subsection{Factors promoting motivation for self-care}

Young adults with type 1 diabetes mellitus described several factors that had a positive impact on their motivation for selfcare. Some factors were perceived as basic conditions, while others were perceived more as a driving force. Moreover, there were factors that affected the attitude towards the illness and how self-care was managed, and this was mirrored in their experience of motivation.

\subsubsection{Feeling safe and getting support}

Motivation for self-care among the young adults interviewed was not constant but varied over time, and self-care was reported as an experience that required time and space. Motivation differed according to specific situations and the overall life situation, and was also dependent on certain prerequisites. Factors that were experienced as promotive were feeling safe, receiving support in everyday life and having control over your own life. In addition, personal maturity and a structured life created possibilities for managing self-care, as did having access to the right aids. According to one of the interviewees, being open about the disease and being able to express personal needs promoted motivation and made self-care easier in everyday life:

"During the last two to three years I've become more open and that's very nice and I feel relieved... I have maybe not accepted it quite yet... But I have become more open about the disease and... I... take better care of myself." (I5)

The acceptance level of the interviewees differed, and they were all in different stages of the acceptance process. Acceptance was a major factor in relation to the will and motivation to take care of one self and one's health. It mirrored how self-care was managed in everyday life. Feeling safe was about receiving practical support from close relationships to take care of the household, to make a sandwich in the middle of the night or to receive a reminder about medication and medical checkups. As in earlier studies ${ }^{[39,40]}$ and in this study, the need to not be left alone and feeling alone with the

Published by Sciedu Press disease and self-care were clearly expressed. To be able to feel safe, it was necessary to have at least one person who knew about the disease, understood it and had knowledge of it, and was supportive and helped with daily life activities.

"You need to have with you at least someone who knows about it. Otherwise it's a little tough. It gives me safety that there is someone that will help with my self-care...no matter what... I have a very good boyfriend who helps me with this... It's a fulltime job to have a chronic disease... you need to be two about it. . you can't manage it all by yourself." (I6)

Emotional support was, above all, about understanding and having someone to talk to without having to explain everything. It was about having someone close by and available when life became difficult or if something unforeseen happened that required a helping hand, for example, if the blood sugar level was too high or low at home, at work or at school. Emotional support was indispensable for the management of the psychological strain associated with a chronic disease such as diabetes type 1 . The young adults in this study confirmed that such psychological strain existed and explained that it manifested itself, for example, in the form of mental exhaustion and agony at night, and also the feeling of being different and feeling powerless when the body was affected by weight gain as a result of the insulin treatment. Having someone close was described both as motivational and as supportive when one's own motivation was diminished, as described in Johnson and Melton's study, where sharing the burden was emphasised as being supportive for managing everyday challenges. ${ }^{[41]}$

The results showed that the interviewees felt motivated after the visit to the nurse at the diabetes clinic. The duration of motivation varied among the interviewees, but none of the interviewees stated that it lasted for more than one month. The diabetes nurse was considered to have in-depth knowledge about diabetes and was able to answer different questions. The nurse gave them sufficient time, and they felt that they could always turn to the nurse for support and guidance. Such continuous support was important, and it was also important for the relationship to be honest and for the nurse and patient to have a good rapport. Even as the interviewees expressed their need to not be left alone with the disease, they mentioned that they wished to be independent and expressed a will to manage on their own. According to Karlsson et al., the development towards an independent adult includes this oscillation between autonomy and seeking relief. ${ }^{[40]}$

\subsubsection{Experiencing control over your own life}

A structured life was a prerequisite for being able to manage self-care in everyday life as well as enhancing motivation, 
as it permitted the space needed to care for the disease and to integrate self-care into routine life. Not having a routine was a hindrance to positive self-care. Sometimes, the personality of the patient was a hindrance, when the will to live an unstructured life took over and had negative consequences. Different helping aids promoted feelings of safety. For example, the ability to check blood sugar levels or having an alarm for low levels during night time promoted a good night's sleep. Different helping aids contributed to having control, such as the monitor for blood sugar levels over time, which helped to maintain stable and good control. This helped the patients manage everyday life, as the aids mirrored their bodily functions and reactions. In that sense, they helped and made it possible to lead a more free life, for example, having meals when they desired. With the right helping aids, the chances of choosing the right occupation or activities based on individual desires were better. Helping aids contributed to feelings of being powerful enough to make the right choices in life and enhanced motivation for self-care. If the user found the aids helpful and enjoyed using them, it was easier for them to keep their motivation levels high.

“... it somehow builds on a motivation... the more control you have the more... I can adjust the lowest and the highest level and then it's almost like a competition. Can I keep it in between? For how long or how many hours? So this must be counted as a motivation I suppose. . " (I7)

The interviewees appreciated active participation and the planning of the care according to the patient's narrative, work and family situation. Furthermore, they appreciated that their individual wishes were taken into account and that care was based on a holistic assessment. Together with the staff, they tried to find solutions and made a care plan. Being able to affect the number of checkups and the fact that the diabetes nurses were considerate of whether an individual wished for more frequent visits were considered as positive aspects of the plan. In addition, the visits to and conversations with the diabetes nurses were strongly motivating. The interviewees mentioned that the conversation with the nurse could be brought up in mind between the visits and strengthened the motivation. However, finding words for and expressing individual needs was not always possible, and the responsibility of making another appointment could sometimes be overwhelming. It was important for the interviewees to be able to make their own decisions regarding which helping aids were needed, and selecting the right helping aid that suited their individual life situation was very motivational. Finally, it was highly appreciated if nursing care was at the cutting edge with regard to technique and if the patients had the opportunity to test new helping aids.

\subsubsection{Striving for wellbeing and meaning}

Striving for wellbeing in the present moment was considered as a driving force that motivated self-care. This included both physical and psychological wellbeing. Feeling better and more positive was motivational for the patients. One of the driving forces for this was the ability to participate in social contexts and having the strength to participate in different activities. The interviewees pointed out that their motivation was enhanced when they approached it from the perspective of taking care of themselves for their own sake. Another dimension that was apparent was finding wellbeing in connection to the body and appearance. As much as wellbeing was connected to motivation for self-care, it was also about feeling good, and this might be considered as the greatest motivational factor in taking care of one self and the diabetes. The interviewees mentioned that if their blood sugar levels were too high or too low they felt tired and anxious, had difficulty concentrating, and experienced mood swings, irritability, anger and trembling. In addition, high levels may affect their nightly sleep negatively as a result of nightmares.

With regard to complications that affect wellbeing from the long-term perspective, the interviewees had different opinions about whether they were motivational factors or not. Wellbeing in the long run was considered as the absence of complications for as long as possible by some interviewees, and this was seen as a driving force. Thinking about their own health from a long-term perspective was considered as a very abstract concept by some interviewees, and in that sense, they did not find it to be a motivational factor. The cognitive maturity in this particular group of patients may mean that they have different values and views concerning how complications can be avoided in the long run. It is therefore important that the care is adapted to the degree of maturity and development of the patients. For some interviewees, the HbA1c value seemed very abstract. In these cases, it is important to focus on short-term indicators such as optimal blood sugar levels. Young adults with diabetes are sometimes left in between because their maturity level is not considered when they are moved from child to adult clinics. ${ }^{[2]}$ Therefore, care should be customized according to individual needs, and specialists in youth medicine as well as those with knowledge of the psychosocial field should be utilized for this particular patient group. ${ }^{[6]}$

Some interviewees revealed that fluctuations in blood sugar levels did not affect their wellbeing at all, and in these cases, wellbeing was not considered as a driving force. However, all the interviewees agreed that positive results were motivational factors. Puberty, which is characterized by fluctuating and transitioning hormones, is a strenuous period in which it 
is difficult to control blood sugar levels. When the teenage period is over and the blood sugar levels are more stable, the fluctuations become milder. This was expressed as feelings of manageability followed by increased motivation for selfcare. According to one of the interviewees, not being able to manage blood sugar levels may have negative consequences:

“... I have difficulties getting lower levels. So I sometimes need to take a little extra dose of insulin without any results. And that affects motivation very much I think... You really feel frustrated." (I5)

The interviewees described how periods of uncontrollable blood sugar levels affected motivation and how this was accompanied by insight about the need for self-care. When feelings of hopelessness appeared, it was managed by a short break that helped them gather new strength and to manage self-care again. Pursuing planned activities created feelings of success that led to motivation. In addition, a positive spiral of weight loss together with lower doses of insulin was experienced as a highly motivational factor. The interviewees emphasised on the importance of diabetes nurses focusing on the positive results to create motivation. Focusing on negative results created an opposite effect, which might lead to a bad conscience. Responding to challenges was considered as a good way of changing a negative trend. This might for instance be an attempt to maintain the blood sugar level within a certain limit over a certain period. In addition, it was important for the interviewees to have positive experiences of success with small endeavours.

The interviewees wished to belong to a context or to a family, and having people who would be there for them created motivation for self-care. It is possible that being free from complications for the sake of the family or being able to see a future together with others created a sense of meaning. Feeling a sense of responsibility for the wellbeing of their close ones in the present moment also gave them meaning. By taking care of themselves and their diabetes, they found that their surroundings were affected in a positive way. Family and close friends contributed to feelings of motivation just by being there, and also by encouraging them. Another factor that motivated self-care was participating in work life or in an association. Being able to work and take care of one's own finances was considered very important. Participating in exercise or leisure activities together with others was also important, as stated by one of the interviewees:

"Being able to play football motivates me to keep a good blood sugar level." (I3)

According to the interviewees, the diabetes nurse played an important role by encouraging and placing diabetes in the right context so as to create meaning through self-care.
"It feels as the diabetes nurse cares about all of me and that feels good. They are good at pep talk. They are good at being objective and to explain how things are and to talk seriously." (I3)

The joint plan was, according to the interviewees, adapted to their everyday life by taking into account their specific conditions. The interviewees found that they were treated in a holistic way, which made them feel motivated after their visits to the clinic.

\subsection{Factors that hindered motivation for self-care}

The vulnerability of young adults to stress, worry and anxiety were expressed as factors that hindered self-care. Their concern about their wellbeing with regard to both appearance and behaviour did not only hinder motivation but also made self-care difficult. Stereotypes and ignorance about the disease were also hindering factors. In particular, feeling vulnerable and feeling excluded were hindering factors for motivation and self-care.

\subsubsection{Feeling vulnerable}

According to the young adults who were interviewed, being part of a stressful society had a negative impact on their self-care. In the face of stressful life events, diabetes was given less importance and their motivation for self-care was affected. That is, self-care was not always given the most important place if other aspects of life seemed more important. In addition, diabetes self-care was considered as a fulltime job in itself, as it was time consuming and constant. This posed a huge mental strain and sometimes even resulted in burn out.

“... there are many thoughts... so I often feel that it can be like a mental fatigue... diabetes thoughts all the time... More mental than physical fatigue... When I feel mentally wornout because it is too much, I don't have strength to control myself." (I5)

As reported in an earlier study, the interviewees stated that they had different strategies that they had developed both unconsciously and consciously in order to manage everyday life with diabetes. ${ }^{[42]}$ One strategy was to consciously skip insulin injections when snacking by thinking that it would be compensated for at the next meal. Another strategy to avoid hypoglycaemia and 'unnecessary' injections was to consciously maintain blood sugar at a higher level. Helping aids were highly appreciated, since they facilitated everyday life activities. The interviewees expressed the need for mental rest, as it helped them avoid thinking about the disease all the time. One way of doing this was to keep busy and keep thoughts about the disease away by engaging in fun activities that occupied the mind. In this regard, helping aids that were 
not connected to the body provided a sense of freedom for a while.

To some extent, the interviewees ignored the disease and their needs. This might occur in different situations but might also be connected with the individual transition from denial to acceptance. The interviewees narrated about feelings of injustice and rebellion and how denial and not being open about the disease might have a negative impact both on motivation and self-care.

"Normally I don't think that I am sick or anything, but. . that makes it a little difficult sometimes when I realize. .. oh my blood sugar is so low and I have not even told anyone here that I have diabetes...just because I don't think or care so much about it..." (I7)

Not bothering to measure the blood sugar level but trusting their own feelings might indicate that the interviewees were ignoring the disease. This always has negative consequences, since feelings about blood sugar levels can be misleading when the body has gotten used to increased levels. Another consequence of denial was that the interviewees were reluctant to accept the risk of complications in the future. However, the knowledge that there might be a need for quick life-changing measures on account of the chronic nature of the disease created worry and anxiety. Fear of death during the night could also occur, especially fear of hypoglycaemia.

"I had a period when I couldn't sleep at night. . I was terrified because nobody was awake. So I lay in my bed and. . tonight I will die. Those were my thoughts every night." (I6)

One strategy to avoid this fear was to consciously have high blood sugar levels at night to be on the safe side. In such cases, fear became a hindrance for the motivation to keep blood sugar levels at an acceptable level. The interviewees felt that helping aids that raised an alarm if the blood sugar level was too low were very helpful. Feelings of being alone with the disease were prominent. Thoughts about how difficult it was for relatives and the diabetes nurse to really understand the life situation of each individual were also revealed. According to the interviewees, it is not enough for someone to be at hand or to have expert knowledge in the field. To fully understand how it really is requires personal experience with the disease.

The importance of helping aids in enhancing motivation was emphasised by all the interviewees in this study: they might therefore contribute to better blood sugar control and lower HbA1c in this young adult patient group. For individuals with diabetes, this means enhanced wellbeing, less complications and a better quality of life. It presents them with the possibility of engaging in work and social life, and is in that sense, a step towards sustainability. An earlier study ${ }^{[43]}$ stated that increased HbA1c levels are associated with high costs to society on account of hospitalization, increased need for insulin and care in relation to complications. In addition, reduced use of insulin and medications have positive effects on the environment.

\subsubsection{Feeling excluded}

Feelings of wanting to fit in and be included had a negative impact on motivation and self-care. This might be reflected in attempts to hide the syringe in public and resultant difficulties in self-care. Helping aids reduced feelings of being special and enabled more discrete self-care. The attempt to "fit" in and follow the norm could be related to the idea of having an ideal body and body image. One interviewee talked about how "insulin buns" at the injection sites made them feel like they were sticking out in the crowd. This was a factor that reduced motivation, as did taking enough insulin, since an increased need for insulin resulted in weight gain.

“... I have had diabetes for a very long time and I have been insulin-resistant and I have had to increase my doses even more... one can follow a curve. . the more I have increased my insulin doses the more weight gain... it's so incredibly dull." (I6)

Meeting with others who are in the same situation might feel liberating and give individuals a sense of being one with the crowd. Feelings of belongingness and not being treated as a diabetic or given any special treatment were considered as important by the interviewees. In some situations, the disease might lead to special treatment and restrictions. The disease might, for example, be a hindering factor in terms of choice of career.

"I applied to the fire brigade. . I managed all tests. . I don't know how they missed it... I have diabetes... So I had to quit... That pulled me deep...” (I8)

The disease could prevent individuals from participating in different activities, which can cause feelings of alienation. The fear of ignorance among the public might be a hindrance to motivation. On the other hand, it was inspiring when public persons with diabetes demonstrated that difficulties could be overcome and that it was possible to lead a normal life. In some cases, the interviewees thought that to be able to lead a normal life, they would not have enough time or space for self-care. The attitude of other people could be perceived as a hindrance to motivation. The interviewees stated that people often commented and questioned them about their meal situations. They also expressed how ignorance in connection with the handling of syringes made self-care difficult.

"Yes, I feel a little ashamed. I have been bawled and ques- 
tioned by pub guards. . because they have thought that it's drugs. . " (I2)

The quote shows how the disease can create a feeling of not being welcome in some situations. It describes how preconceived opinions and stereotypes can prevent individuals with diabetes from participating on the same terms as others. The interviewees talked about how they felt that they were in the limelight when others cast glances at them when they were using their helping aids. They also expressed a fear of being met by ignorance, especially in situations where they were hypoglycaemic but mistaken as being drunk. According to the findings from the interviews, motivation increases with positive responses from care providers. Therefore, it is very important that doctors and nurses have a positive approach when young adults present for checkups. Trying to identify and point out positive changes is of great meaning for motivation and self-care. ${ }^{[41]}$ The focus should be on health and the good experiences of life. The interviewees emphasised on the possibility of being able to participate in different activities, so perhaps this should also be the focus in care to maximize conditions that create opportunities.

\section{Limitations of the study}

A limitation of this study is that only eight informants participated and all were between twenty and twenty-five years old. However, all participants narrated willingly, and the interviews provided rich material as is shown in the quotes. The findings in this study are consistent with earlier studies, which strengthens the evidence and the trustworthiness of this study.

\section{Conclusions}

The findings in this study confirm, in many aspects, the results in earlier studies, but also new information occurs. The great importance of a caring and supporting relationship with the care providers is evident. Continuity and regular checkups play an important role in promoting the motivation for self-care. The young adults have specific needs and want an individualized and holistic care where they are seen as a whole person and not solely as a patient with type 1 diabetes. To belong to a family or a context and to be able to take part in social activities is important. Young adults value emotional support generated in group sessions, collaborative relationships and joint decision-making with care providers. Diabetes self-care is time consuming and a mental strain. Different helping aids enhance motivation and are highly valued, since they help the patients manage everyday life and provide relief and a sense of control. To meet the needs of the young-adult population calls for more innovative and flexible methods and patient engagement.

\section{ACKNOWLEDGeMENTS}

We thank all young adults that participated in this study and made it possible.

\section{CONFlicts OF InTEREST Disclosure}

The authors declare they have no conflicts of interest.

\section{REFERENCES}

[1] International Diabetes Federation. Diabetes Atlas. 8th ed. UK; 2017.

[2] Swedish society for diabetology. Nationella Diabetesregistret [The national register of diabete]. Gothenburg, Sweden; 2016.

[3] National guidelines for Diabetes Care. Support for governance and management. Stockholm, Sweden: The National Board of Health and Welfare; 2015.

[4] Hynes L, Byrne M, Casey D, et al. 'It makes a difference coming here': A qualitative exploration of clinic attendence among young adults with type 1 diabetes. Brittish Journal of Health Psychology. 2015; 20: 842-858. PMid: 26118734. https://doi.org/10.111 $1 /$ bjhp. 12145

[5] Lancaster BM, Pfeffer B, McElligott M, et al. Assessing treatment barriers in young adults wirh type 1 diabetes. Diabetes Research and Clinical Practice. 2010; 90(3): 243-249. PMid: 21035226. https://doi.org/10.1016/j.diabres.2010.07.003

[6] Peters A, Laffel L. Diabetes Care for Emerging Adults: Recommendations for Transition From Pediatric to Adult Diabetes Care Systems. Diabetes Care. 2011; 34(11): 2477-2485. PMid: 22025785. https://doi.org/10.2337/dc11-1723

[7] Nordwall M, Abrahamsson M, Dhir M, et al. Impact of HbA1c, Followed From Onset of Type 1 Diabetes, on the Development of Severe
Retinopathy and Nephropathy: The VISS Study (Vascular Diabetic Complications in Southeast Sweden). Diabetes Care. 2014; 38(2): 308-315. PMid: 25510400. https://doi.org/10.2337/dc14-1 203

[8] Monaghan M, HelgesonV, Wiebe D. Type 1 Diabetes in Young Adulthood. Current Diabetes Review. 2015; 11(4): 239-250. https : //doi.org/10.2174/1573399811666150421114957

[9] Smith C, Christoffersen K, Davidson H, et al. Lost in Transition: The Dark Side of Emerging Adulthood. New York: Oxford University Press; 2011. https://doi .org/10.1093/acprof : oso/978019 9828029.001 .0001

[10] Arnett JJ. Emerging adulthood: A theory of development from the late teens through the twenties. American Pshychologist. 2000; 55(5): 469-480. https://doi.org/10.1037/0003-066X.55.5.469

[11] Perry L, Steinbeck KS, Dunbabin JS, et al. Lost in transition? Access to and uptake of adult health services and outcomes for young people with type 1 diabete in regional New South Wales. Medical Journal of Australia. 2010; 193: 444-449. PMid: 20955120.

[12] Sparud-Lundin C, Öhrn I, Danielson E. Redefining relationships and identity in young adults with type 1 diabetes. Journal of Advanced Nursing. 2010; 66(1): 128-138. PMid: 20423440. https: //doi.org/10.1111/j.1365-2648.2009.05166.x 
[13] Johnson B, Elliott J, Scott A, et al. Medical and psychological outcomes for young adults with type 1 diabetes: No improvement despite recent advances in diabetes care. Diabetic Medicine. 2014; 31: 227 231. PMid: 23952498. https ://doi.org/10.1111/dme. 12305

[14] Lane JT, Fergusson A, Hall J, et al. Glycemic control over 3 years in a young adult clinic for patients with type 1 diabetes. Diabetes Research and Clinical Practice. 2007; 19(3): 385-391. PMid: 17602780. https ://doi.org/10.1016/j.diabres.2007.04.014

[15] Garvey KC, Wolpert HA, Laffel LM, et al. Health care transition in young adults with type 1 diabetes: barriers to timely establishment of adult diabetes care. Endocrine Practice. 2013; 19(6): 946-952. PMid: 23807526. https://doi.org/10.4158/EP13109.OR

[16] Mistry B, Van Blyderveen S, Punthakee Z, et al. Condition-related predictors of successful transition from paediatric to adult care among adolescents with type 1 diabetes. Diabetic Medicine. 2015; 32(7): 881-885. PMid: 25764182. https://doi.org/10.1111/dme.12 746

[17] Balfe M, Brugha R, Smith D, et al. Considering quality of care for young adults with diabetes in Ireland. BMC Health Services Research 2013; 13: 448. PMid: 24168159. https ://doi.org/10.1186/14 72-6963-13-448

[18] Markowitz JT, Laffel MB. Short Report: Education and Psychological Aspects Transitions in care: support group for young adults with Type 1 diabetes. Diabetic Medicin. 2012; 29(4): 522-525. PMid: 22150392. https://doi.org/10.1111/j.1464-5491.2011.0 $3537 . \mathrm{x}$

[19] Scholes C, Mandleco B, Roper S, et al. A qualitative study of young people's perspectives on living with type 1 diabetes: do perceptions vary by levels of metabolic control? Journal of Advanced Nursing. 2013; 69(6): 1235-1247. PMid: 22861071. https : //doi.org/10.1111/j.1365-2648.2012.06111.x

[20] Wiley J, Westbrook M, Long J, et al. Multidisciplinary diabetes team care: the experiences of young adults with Type 1 diabetes. Health Expectations. 2015; 18(5): 1783-1796. PMid: 24345040. https://doi.org/10.1111/hex.12170

[21] Peters A, Laffel L. Diabetes Care for Emerging Adults: Recommendations for Transition From Pediatric to Adult Diabetes Care Systems. Diabetes Care. 2011; 34: 2477-2485. PMid: 22025785. https://doi.org/10.2337/dc11-1723

[22] Brady PJ, Song HJ, Butler J. Using an Expert Panel to Develop Social Support Program Sequencing for Young Adults With Type 1 Diabetes. Health Promotion Practice. 2017; 18(6): 789-797. PMid: 28760008. https://doi.org/10.1177/1524839917720934

[23] Findley MK, Cha E, Wong E, et al. A systematic review of transitional care for emerging adults with diabetes. Journal of Pediatric Nursing. 2015; 30(5): e47-62. PMid: 26164412. https: //doi.org/10.1016/j.pedn.2015.05.019

[24] Monaghan M, Hilliard M, Sweenie R, et al. Transition readiness in adolescents and emerging adults with diabetes: The role of patientprovider communication. Current Diabetes Reports. 2013; 13(6): 900-908. PMid: 24014075. https://doi.org/10.1007/s11892 -013-0420-x

[25] Ritholz MD, Wolpert H, Beste M, et al. Patient-provider relationships across the transition from pediatric to adult diabetes care: A qualitative study. The Diabetes Educator. 2014; 40(1): 40-47. PMid: 24258251. https://doi.org/10.1177/0145721713513177

[26] Rutishauser C, Sawyer SM, Ambresin AE. Transition of young people with chronic conditions: A cross-sectional study of patient perceptions before and after transfer from pediatric to adult health care. European Journal of Pediatrics. 2014; 173(8): 1067-1074. PMid: 24610395. https://doi.org/10.1007/s00431-014-2291-9
[27] Zoni S, Verga ME, Hauschild M, et al. Patient Perspectives on Nurse-led Consultations Within a Pilot Structured Transition Program for Young Adults Moving From an Academic Tertriary Setting to Community-based Type 1 Diabetes Care. Journal of Pediatric Nursing. 2018; 38: 99-105. PMid: 29357987. https ://doi.org/ $10.1016 / j \cdot$ pedn .2017 .11 .015

[28] Price CS, Corbett S, Lewis-Barned N, et al. Implementing a transition pathway in diabetes: A qualitative study of the experiences and suggestions of young people with diabetes. Child: Care, Health and Development. 2011; 37(6): 852-860. https://doi.org/10.111 $1 / \mathrm{j} .1365-2214.2011 .01241 . \mathrm{x}$

[29] Hilliard ME, Perlus JG, Clark LM, et al. Perspectives from before and after the pediatric to adult care transition: A mixed-methods study in type 1 diabetes. Diabetes Care. 2014; 37(2): 346-35. PMid: 24089544. https://doi.org/10.2337/dc13-1346

[30] Burns K, Farrell K, Myszka R, et al. Access to a youth-specific service for young adults with type 1 diabetes mellitus is associated with decreased hospital length of stay for diabetic ketoacidosis. Internal Medicine Journal. 2018; 48: 396-402. PMid: 29034986 https://doi.org/10.1111/imj.13649

[31] Bendt A. Diabetes typ 1 hos barn [Diabetes type 1 among children]. 2016. In Swedish.

[32] The Diabetes Manual. Diabeteshandboken. Vad gör man på en diabeteskontroll? 2015. In Swedish. Available from: http://www.diabeteshandboken.se/innehåll/16.-vad-g öra-på-en-diabeteskontroll-13754637

[33] The project "The Elevator". Södra Älvsborgs sjukhus [The Medical clinic]. 2017. In Swedish. Unpublished manuscript.

[34] World Health Organisation. Ottawa charter for health promotion. Copenhagen: WHO; 1986.

[35] Polit D, Beck C. Nursing Research: Appraising Evidence for Nursing Practice. 7th ed. Philadelphia: Lippincott, Williams \& Wilkins; 2010.

[36] Graneheim UH, Lundman B. Qualitative content analysis research: concepts, procedures and measures to achieve trustworthiness. Nurse Education Today. 2004; 24: 105-112. PMid: 14769454. https: //doi.org/10.1016/j.nedt.2003.10.001

[37] Swedish Law. 2008; 192.

[38] Swedish Research Council, Good Research Practice. Stockholm. 2011.

[39] Carroll A, Marrero D. The role of significant others in adolescent diabetes: a qualitative study. The Diabetes Educator. 2006; 32(2): 243-252. PMid: 16554428. https ://doi .org/10.1177/014572 1706286893

[40] Karlsson A, Arman M, Wikblad K. Teenagers with type 1 diabetes - a phenomenological study of the transition towards autonomy in self-management. International Journal of Nursing Studies. 2008; 45: 562-570. PMid: 17046768. https://doi.org/10.1016/j.ijnu rstu. 2006.08.022

[41] Johnson N, Melton S. Young Adults with Type 1 Diabetes: How to Help. Adolesc Med State Art Rev. 2013; 24(3): 621-628. PMid: 24654552.

[42] Rasmussen B, Ward G, Jenkins A, et al. Young adults' management of Type 1 diabetes during life transitions. Journal of Clinical Nursing. 2011; 20(13/14): 1981-1992. PMid: 21545569. https : //doi.org/10.1111/j.1365-2702.2010.03657.x

[43] Franciosi M, Lucisano G, Amoretti R, et al. Costs of treatment and complications of adult type 1 diabetes. Nutrition, Metabolism \& Cardiovascular Diseases. 2013; 23: 606-611. PMid: 22749531. https ://doi.org/10.1016/j.numecd.2012.03.002 